\title{
Microstructure and mechanical properties of AA6082-T6 by ECAP under warm processing
}

T. Khelfa ${ }^{1 *}$, J. A. Muñoz-Bolaños ${ }^{2}$, J. M. Cabrera-Marrero ${ }^{2}$, M. Khitouni ${ }^{1}$

\footnotetext{
${ }^{1}$ Laboratory of Inorganic Chemistry Ur-11-ES-73, Faculty of Sciences, University of Sfax, 1171, 3018-Sfax, Tunisia.

${ }^{2}$ Department of Materials Science and Metallurgical Engineering, Universitat Politècnica de Catalunya, EEBEc/Eduard Maristany 10-14, 08019 - Barcelona, Spain.
}

\begin{abstract}
An AA6082 alloy deformed by equal channel angular pressing (ECAP) was studied. The evolution of microstructure as a function of the strain imparted was evaluated by optical microscopy (OM), scanning electron microscopy (SEM) coupled with an electron backscattered diffraction (EBSD) detector, X-ray diffraction (XRD) and Differential Scanning Calorimetry (DSC). XRD showed that $\mathrm{MgSi}_{2}$ precipitates developed in the ECAPed specimens. Texture analysis showed the apparition of two types of textures, one associated with shearing deformation and the second due to the recrystallization phenomena. Mechanical strength properties measured by tensile tests increased in the first ECAP pass, and then progressively diminished. This phenomenon was associated to the activation of continuous softening phenomena. Calorimetric analysis indicated a slightly rise in the recrystallization temperature of the deformed specimens. Also, the stored energy increased with rising ECAP passes due to the production of new dislocations. The average geometrically necessary dislocation (GND) density, measured by EBSD, increased with increasing ECAP passes. However, the rate of increase slows down with the progress of ECAP passes.
\end{abstract}

\section{Keywords}

6082 aluminum alloy; Microstructural evolution; Texture evolution; Mechanical properties; Stored energy.

*Corresponding author: tarekkhelfa@yahoo.fr (T.K)

\section{Introduction}


Severe plastic deformation (SPD) techniques have been intensively used to produce ultrafine grain (UFG) microstructures in metals and alloys [1]. One of the most popular and feasible SPD methods is the equal channel angular pressing (ECAP). ECAP is an efficient technique for reducing the grain size to submicrometer level through the introduction of a wide plastic strain via repetitive processing. This technique requires the pressing of a billet via a die composed by two channels with equal cross-sections, intersecting at an angle $\Phi$ that usually ranges from $90^{\circ}$ to $157^{\circ}$ [2]. This process has been applied to several metallic materials leading to significant grain refinement and enhancements in mechanical properties $[3,4]$. Yield strength of the material rises significantly after the first ECAP, and then increases progressively as further strain in subsequent passes are applied. On the contrary, the elongation to failure considerably diminishes after the first pass and keeps nearly the same after subsequent passes [5].

Al-Mg-Si alloys are intensively utilized for structural applications owing to their excellent chemical and physical properties. The alloy with the designation AA6082 is classified to be the hardest alloy in the 6000 family. High weldability, low density and good formability, all along with low cost, are facts that made of this alloy one of the most commercially demanded. One of the useful ways by which aluminum alloys can obtain further superior mechanical properties is grain refinement. Thanks to the formation of UFG structures, an apparent improvement in mechanical properties such as strength and hardness can be obtained without severe penalty on ductility [6].

During the last decades, several metals and alloys were successfully processed by ECAP. However, hexagonal closed-packed alloys (such as titanium and magnesium-based alloys) and age-hardenable alloys (such as aluminum alloys) displayed several difficulties while being processed by ECAP at ambient temperature. Practically the formation of precipitates in the solution treated age-hardenable $\mathrm{Al}$ alloys promotes a heavy decrease of the material formability, and under this condition the processed materials displayed cracking or segmentation in the 
samples [7,8]. However, these problems may be solved by rising the processing temperature [9] and altering the channel angle in the die [10]. Nevertheless, an increase at the pressing temperature must be carefully done to avoid further precipitation (or even overaging) and microstructural restoration in the form of conventional recrystallization and grain growth [11]. Accordingly, Baig et al. [7] come up with a new strategy for the ECAP processing of AA6082 at ambient temperature and discovered that ECAP processing may be performed successfully, without a remarkable catastrophic cracking or segmentation, if ECAP processing is conducted immediately after quenching from the solution treatment. Accordingly, aging is carried out after deformation. Other authors have extruded aluminum alloys in the over aged condition $[11,12]$. The goal of this study was to process by ECAP the AA6082 at warm temperature avoiding sample cracking and segmentation as well as the evaluation of the ECAP efficiency to reach good mechanical properties under warm processing conditions. Finally, the evolution of the microstructure, texture and mechanical properties on the ECAP passes was also studied.

\section{Material and experimental details}

The chemical composition of this alloy, evaluated by spark emission spectrometer, is listed in Table 1. Rods were divided into cylinders having $60 \mathrm{~mm}$ length and $10 \mathrm{~mm}$ diameter. They were solution treated (ST) at $530^{\circ} \mathrm{C}$ for $2 \mathrm{~h}$ and then water quenched prior to ECAP. Fig 1a shows the ECAP die geometry, corresponding to a theoretical strain of $\sim 1$ per pass [12]. To avoid cracking and segmentation of the rods (see Fig.1b), the ECAP processing was performed at $250^{\circ} \mathrm{C}$ via route $\mathrm{B}_{\mathrm{C}}$, i.e. the billet is rotated in the same sense by $90^{\circ}$ about its longitudinal axis between each pass. It was expected to obtain the maximum precipitation of $\beta$ "- $\mathrm{Mg}_{2} \mathrm{Si}$ (hardening phase) from the $\mathrm{Al}$ matrix with the chosen temperature of $250{ }^{\circ} \mathrm{C}$. Specimens were held inside the ECAP die for 5 min (already at $250 \mathrm{C}^{\circ}$ ) before pressing $[13,14]$. This process was performed up to eight ECAP passes. Molybdenum disulfide $\left(\mathrm{MoS}_{2}\right)$ was used as lubricant and the pressing speed was set to $0.02 \mathrm{~m} / \mathrm{s}$. 
The microstructures of the specimens were investigated by optical microscopy $(\mathrm{OM})$ with an Olympus GX51 microscope and by electron backscatter diffraction (EBSD) in a FEG-SEM ZEISS Ultra Plus scanning electron microscope (SEM), operating at $20 \mathrm{kV}$. The EBSD data was studied using the HKL Channel 5 software. Geometrically Necessary Dislocations (GNDs) were obtained by MTEX tool box.

For this goal, samples were cut from the center of each billet. The metallographic specimens for $\mathrm{OM}$ were prepared by mechanical polishing and etched with a special reagent $(30 \mathrm{ml} \mathrm{HCl}+$ $40 \mathrm{ml} \mathrm{HNO} 3+3.5 \mathrm{ml} \mathrm{HF}+3.5 \mathrm{ml} \mathrm{H} 2 \mathrm{O}$ ) [15]. The ECAPed specimens for EBSD observation were cut from the central region in the transversal plane (XY), as described in Figure 1a, where the axes of the reference system coincide with the extrusion direction " $\mathrm{X}$ " (ED), the normal direction "Y" (ND) and the transversal direction "Z" (TD). These samples were mechanically polished using standard metallographic procedures until $0.02 \mu \mathrm{m}$ colloidal silica suspension.

To identify the phase composition present after ECAP, a Philips Xpert Pro diffractometer was used, employing $\mathrm{Cu} \mathrm{K} \alpha$ radiation $(\lambda=1.5406 \AA$ ). Specimens preparation for X-ray diffraction measurements mainly consisted of mechanically polishing the examined specimens with 1000 grade $\mathrm{SiC}$ paper and then etching with Keller's solution $\left(95 \mathrm{ml} \mathrm{H}_{2} \mathrm{O}+2.5 \mathrm{ml} \mathrm{HNO}_{3}+\right.$ $1.5 \mathrm{ml} \mathrm{HCl}+1 \mathrm{ml} \mathrm{HF})$.

Mechanical properties of ECAPed specimens were also measured in longitudinal direction by tensile tests with specimens having a standard gauge dimension of $6 \times 3 \times 2 \mathrm{~mm}$. The tensile tests were carried out in an INSTRON 5585H universal testing machine at a displacement rate of $3.3 \times 10^{-3} \mathrm{~mm} / \mathrm{s}$ (strain rate of $5.5 \times 10^{-4} \mathrm{~s}^{-1}$ ) at room temperature.

In order to clarify the precipitation sequence and the peak temperatures, miniature specimens of 20-35 mg were cut near the axial center of the as-pressed specimens and they were subjected to Differential Scanning Calorimetry (DSC) analysis by using a Labsys Evo $\left(800{ }^{\circ} \mathrm{C}\right)$ 
facility with a heating rate of $20{ }^{\circ} \mathrm{C} \mathrm{min}^{-1}$ under argon atmosphere and in the temperature range from 30 to $550{ }^{\circ} \mathrm{C}$.

\section{Results and discussion}

\subsection{Initial microstructure before ECAP}

Figure 2 shows the initial microstructure of the extruded AA6082-T6 aluminum alloy in the as-received state and before ECAP. Coarse and very elongated grains along the ED are apparent in the optical micrograph in Figure 2a. Moreover, the EBSD micrograph of the alloy after solution treatment still displays elongated grains along ED with dimensions of $\sim 15 \mu \mathrm{m}$ and $\sim 50 \mu \mathrm{m}$ along the transverse and longitudinal directions, respectively (Fig.2b). The black and white lines in the EBSD maps indicate the location of high angle grain boundaries (HAGBs) (misorientations $\theta \geq 15^{\circ}$ ) and low angle grain boundaries (LAGBs) (misorientation of $3^{\circ} \leq \theta$ $\leq 15^{\circ}$ ), respectively. As shown inset of Figure $2 \mathrm{~b}$, the color of each grain is coded by its crystal orientation based on [001] inverse pole figure (IPF) of aluminum. It is remarkable that although the sample is solution-treated, a relatively high substructure (LAGB's) within the interior of elongated grains is noticed, especially in those grains with a $<111>$ orientation. Figure $2 \mathrm{c}$ displays the correlated distribution of grain boundaries misorientation, indicating a proportion of HAGB of $\sim 67 \%$ while the average misorientation is $\sim 29.63^{\circ}$. Meanwhile, the typical XRD pattern in Figure $2 \mathrm{~d}$ shows that the phases in undeformed AA6082 alloy after solution treatment are the $\alpha$ (Al) matrix and a series on intermetallic compounds, namely $\mathrm{Al}_{12}(\mathrm{Fe}, \mathrm{Mn})_{3} \mathrm{Si}, \mathrm{AlMn}$ and $\mathrm{AlMnSi}$ $[16,17]$. According to Kumar et al [16], the insoluble dispersoids of $\mathrm{Al}_{12}(\mathrm{Fe}, \mathrm{Mn})_{3} \mathrm{Si}$ which are present even after performing the solution treatment at high temperature, results in an extension of the Fe solubility into the AlMnSi phase.

\subsection{Microstructure evolution after different ECAP passes}

The orientation maps obtained after 1, 2, 4, 6 and 8 ECAP passes are displayed in Figure 3. Figure 4a shows that the alloy after the first ECAP pass exhibits elongated grains with an 
average grain size around $3.64 \mu \mathrm{m}$ and with a well-developed subgrain microstructure. The microstructure at this condition is mostly formed by LAGB with a preferential orientation towards <111> direction (Fig.3a). After the second ECAP pass, as shown in (Fig.3b), the microstructure still has the same aspect of the elongated structure after one single ECAP pass but a preferential orientation change from $\langle 111\rangle$ to $\langle 101\rangle$. The bands in this step were $1.67 \mu \mathrm{m}$ in width. It can be seen in Fig. $3 \mathrm{c}$ that material with 4 ECAP passes presents a mixed microstructure and texture described by elongated and equiaxed grains (average grain size around $0.93 \mu \mathrm{m}$ ) with preferential orientation in its grains between $<100\rangle$ and $<111\rangle$ directions. With increasing strain ( $\mathrm{N}=6 \sim 8$ passes) the initially high fraction of LAGBs transforms into HAGB (see Fig. 3d-3e) following the mechanisms described by the phenomenon known as continuous dynamic recrystallization $(\mathrm{CDRX})$. In addition, the average grain sizes are around $1.02 \mu \mathrm{m}$ and $0.73 \mu \mathrm{m}$ after 6 and 8 ECAP passes, respectively (see Fig. 3d-3e), sharing orientation in their grains between the $<111>$ and $<101>$ directions. According to Beyerlein et al.[18] the continuous texture changes observed in Figure 3 can be attributed to the change in the deformation plane as the $\mathrm{Bc}$ processing route indicates.

The misorientation distributions as a function of the number of passes together with the HAGB fraction ( $\left.f_{\mathrm{HAGB}}\right)$ and the average misorientation $\left(\theta_{\mathrm{av}}\right)$ are shown in Figure 4. It is observed that $\theta_{\mathrm{av}}$ rises continuously by increasing the ECAP pass number in a similar way than $\mathrm{f}_{\mathrm{HAGB}}$. After one ECAP pass, more than $75 \%$ of the boundaries correspond to LAGB (Fig.4a). Up to the fourth ECAP pass, the misorientation distribution is gradually displaced towards higher angles, and the $\mathrm{f}_{\mathrm{HAGB}}$ progressively rises (Fig.4b-c) achieving $~ 49 \%$ after 4 ECAP passes and $~ 57 \%$ after 8 ECAP passes, as displayed in Figures 4d-e, respectively. The slow evolution of HAGB in the present alloy can be explained by the existence of solute atoms, which delay the recovery rate, and therefore prevent HAGB to be formed. Indeed, an interesting remark from Fig.4e is the 
fact that after eighth ECAP passes, the misorientation distribution is quite like the random distribution predicted by Mackenzie [19].

The evolution of the HAGB and LAGB fractions of the present alloy as a function of the ECAP passes are better illustrated in Figure 4f. It is apparent that the ECAPed alloy generates a large amount of subgrains in the first pass, which decreases gradually with increasing the ECAP passes, as already stated. In the early SPD stage, geometrically necessary boundaries (GNBs) are created to subdivide the coarse grains into cell blocks. For that reason, in the first ECAP pass one can observe a high LAGB fraction, while in the following ECAP passes (2, 4, 6 and 8 passes), once continuous dynamic recrystallization takes place, the HAGB number increases continuously. Accordingly, the transformation of LAGB into HAGB is controlled by the recovery rate. In this sense, if one compares the evolution of HAGBs of AA6082 with the results reported by Subbarayan et al. [20] for pure Al ECAPed at $250{ }^{\circ} \mathrm{C}$, it is revealed that the large $\mathrm{Mg}$ content in the present alloy must be behind the diminution of the recovery rate, [14].

On the other hand, Figure 5 illustrates the variation of average grain size as a function of ECAP passes. The average grain size of the unprocessed specimen was $\sim 32 \mu \mathrm{m}$. After the first ECAP pass, the grain size decreases rapidly to $\sim 3.64 \mu \mathrm{m}$. Subsequently, the grain size decreases gradually to $0.73 \mu \mathrm{m}$ after 8 ECAP passes. Interestingly, the present evolution in the AA6082 alloy at elevated temperature is very similar to the evolution noticed in AA6060 ECAPed at room temperature [21]. This later alloy has an average grain size around to $0.5 \mu \mathrm{m}$ after 8 passes, whereas the present work indicates an average grain size close to $0.73 \mu \mathrm{m}$. Similar results have been reported by other authors $[13,22]$. Particularly interesting are the results of Subbarayan et al. [20] on ECAPed pure $\mathrm{Al}$ at $250^{\circ} \mathrm{C}$ by route $\mathrm{B}_{\mathrm{C}}$ as the obtained mean grain size of $4 \mu \mathrm{m}$ after 8 passes. This difference of the average grain size was already explained by Mazurina et al. [22] based on the effect of the dispersoids and precipitates delaying any strain relaxation within the grains. However, other authors [23, 24] have reported that in heat treatable aluminum alloys 
(AA7034 and AA2024) where precipitation is one of the dominant strengthening mechanism,

ECAP processing is able to introduce a wide dislocations number within the grains, which then, become potential sites for precipitation nucleation, enhancing therefore the hardening ability, and offering an additional mechanism to delay the recovery kinetics even at elevated temperature.

\subsection{X-ray diffraction of samples after different ECAP passes}

The X-ray diffraction patterns of the present AA6082 alloy processed through ECAP until 8 passes are shown in Figure 6. It is clear from the undeformed sample that $\mathrm{Al}_{12}(\mathrm{Fe}, \mathrm{Mn})_{3} \mathrm{Si}$, AlMnSi and AlMn dispersoids remain insoluble after ST. After one ECAP pass, only the major peaks corresponding to the AlMnSi and AlMn dispersoids are visible, indicating that they remain insoluble. This behavior is very similar to Kumar et al's. [17] results for an CRed AA6082 at room temperature. By increasing the ECAP passes, a small peak around $2 \theta=41^{\circ}$ is noticed since the third pass. This peak can be attributed to the $\mathrm{Mg}_{2} \mathrm{Si}$ phase [25]. Furthermore, the intensity of $\mathrm{Mg}_{2} \mathrm{Si}$ peak increases while increasing the amount of deformation (ECAP passes). These results are in agreement with Kumar et al. [16] for an AA6082 alloy after Cryorolling followed by warm rolling at $100-250^{\circ} \mathrm{C}$.

The crystallite size $\langle\mathrm{D}\rangle$ and the lattice strain $\left\langle\varepsilon^{2}\right\rangle^{1 / 2}$ were calculated from the peak broadening ( $\beta$ ) using the Halder-Wagner (HW) method [26] as given below:

$$
\left(\frac{\beta^{*}}{d^{*}}\right)^{2}=\frac{1}{D} \cdot \frac{\beta^{*}}{\left(d^{*}\right)^{2}}+\left(\frac{\varepsilon}{2}\right)^{2}
$$

where $\beta^{*}=\beta \cos \theta / \lambda$ and $\mathrm{d}^{*}=2 \sin \theta / \lambda ; \theta$ is the Bragg angle and $\lambda$ is the wavelength used.

The crystallite size $\langle\mathrm{D}\rangle$ and the lattice strain $\left\langle\varepsilon^{2}\right\rangle^{1 / 2}$ are obtained by drawing a plot between $\left(\frac{\beta^{*}}{d^{*}}\right)^{2}$ (ordinate) and $\frac{\beta^{*}}{\left(d^{*}\right)^{2}}$ (abscissa), being the intercept and slope respectively of the straight lines obtained (see Fig.7). The values of the crystallite size $\langle\mathrm{D}\rangle$ and lattice strain $\left\langle\varepsilon^{2}\right\rangle^{1 / 2}$ 
were then used to calculate the dislocation density $\left(\rho_{D}\right)$ in the ECAPed alloy according to the following equation [27]:

$$
\rho_{D}=2 \sqrt{3} \frac{<\varepsilon^{2}>^{1 / 2}}{<D>\times b}
$$

where $\mathrm{b}$ is the Burgers vector ( $b=a \frac{\sqrt{2}}{2}$ for FCC crystals, being $a$ the lattice parameter). The crystallite size, lattice strain and dislocation density of the ECAPed alloy are listed in Table 2.

A very small $\langle D\rangle$ is observed since the early first ECAP passes accompanied by a substantial amount in lattice strain $\varepsilon$ due to the large amount of deformation introduced by each ECAP pass. From the $2^{\text {nd }}$ to the $8^{\text {th }}$ ECAP passes, no strong or systematic variations are observed either in $<\mathrm{D}\rangle$ or $\left\langle\varepsilon^{2}\right\rangle^{1 / 2}$. In fact, one can estimate an average value about $54 \mathrm{~nm}$ and $0.4 \%$, respectively. This behavior is consistent with results for an ECAPed AA6060 alloy at ambient temperature [21]. Furthermore, it is evident from Table 2 that the dislocation density ( $\rho$ ) increased significantly from $10^{12} \mathrm{~m}^{-2}$ to $11.67 \cdot 10^{14} \mathrm{~m}^{-2}$ as the number of ECAP passes increased from 0 to 2 and then slightly decreased to about $7 \cdot 10^{14} \mathrm{~m}^{-2}$ after eight passes. This decrease can be explained in terms of the development of continuous recovery and dynamic recrystallization.

\subsection{Texture evolution}

Figure 8 indicates the texture evolution using Pole Figures (PFs) and orientation Distribution Functions (ODFs) at different number of ECAP passes. The texture analysis was done following the ideal orientation components for ECAP and recrystallization described by 
Humphreys el al. [28], which are summarized in Table 3. To see the ECAP and recrystallization components the texture was analyzed on both the TD plane and the ND plane.

It can be observed in Figures 8 and 9 that the initial material ( 0 pass $)$ texture presents some rolling and recrystallization components. It was found the existence of several components like R, Brass, Copper and S, but with a small fraction of grains following those orientations. This could be attributed to the solution treatment applied before the ECAP process, which gave rise to a random texture, similar to the investigation of Zhang et al. [29] for AA6011 alloy before rolling deformation. On the other hand, after the first ECAP pass the texture totally changes with the apparition of shearing and recrystallization components. It can be seen in Figure 9a the apparition of all ECAP texture components with the $\overline{\mathrm{B}}$ component as the most important. This behavior is very similar to Wronski et al. [30] results for an ECAPed Aluminium at room temperature where they also found the existence of the $\bar{B}$ as the most intense at the early stage of deformation. On the other hand, it was also observed in Figure $9 \mathrm{~b}$ the important apparition of recrystallization texture components such as $\mathrm{P}$ and Brass. The formation of those recrystallization components could be associated with the processing temperature involved in each ECAP pass. Under these conditions, it is possible that both Continuous Dynamic Recrystallization (CDRX) and Discontinuous Dynamic Recrystallization (DDRX) took place.

It worth mentioning that after 2 ECAP passes the texture is still dominated by the shearing components. As can be observed in Figs. 9a and 9b, after 2 ECAP passes, the main texture components were A1 and B. On the other hand, after 4 and 8 ECAP passes, the material texture changed from shearing components towards recrystallization texture components. For that reason, it was observed in Fig. $9 \mathrm{~b}$ a great fraction of grains following the orientation of components like R, Brass, Copper, S and Dillamore. 
Accordingly, it can be stablished that the texture evolution of the AA6082 alloy processed by ECAP at warm conditions until 8 passes presents two behaviors: the first one, with deformations lower than the second pass where the texture was mainly dominated by the presence of shear components. The second behavior, with deformations higher than 4 passes where the texture was dominated by the presence of recrystallization components. This texture change could explain the fact the texture intensity never decreases even after 8 passes, which is something expected after severe plastic deformation as for e.g. in the research work of Muñoz et al. [31].

The recrystallization texture obtained after 4 and 8 ECAP passes can be attributed to the occurrence of recovery and recrystallization phenomena. This is coherent with the reduction of the dislocation densities observed after 2 passes in Table 2. For that reason, it can be expected that after 2 ECAP passes the SPD process for this alloy with the chosen processing temperature is not efficient as a tool to improve the mechanical properties.

\subsection{Mechanical properties}

Figure 10a shows the engineering stress-strain curves for the present AA6082 alloy after ECAP as a function of the number of ECAP passes. The mechanical properties extracted from the tensile tests including yield stress (YS), ultimate tensile strength (UTS) and percentage of elongation to failure are displayed in Figure 10b. YS and UTS increase simultaneously in the first ECAP pass and then decrease progressively until 8 passes. In absolute values, the YS rises from 172 to $274 \mathrm{MPa}$ after one ECAP pass and then diminishes to $168 \mathrm{MPa}$ after $8 \mathrm{ECAP}$ passes. Similar YS values after one ECAP pass were found between the present study (274 MPa) and the investigation of Baig et al. [7] (255 MPa) for a similar alloy ( ST + over aging treatment) under room temperature processing conditions. This observation indicates and confirms that the warm processing conditions still favor the material strength increase until the first pass. For that reason, it is observed in Figs. 10a and 10b that after one pass the YS stress was $\sim 1$ time larger 
than material without ECAP passes. The increase of strengths (YS and UTS) in the first ECAP pass can be due to several factors such as the effect of decreasing the grain size, the increase of the precipitation of the intermetallic phases in the matrix of the material and also to the wide quantity of dislocations introduced in the process of deformation, or in other words, due to the substructuration that the material is undergoing, as it is obvious in Table 2 with the dislocations increments. On the other hand, the subsequent decrease of strength in further ECAP passes can be explained by the occurrence of dynamic recovery and discontinuous dynamic recrystallization, which leads to the elimination of dislocations. It is accepted that in severely deformed materials diffusivity can be enhanced by the large amount of dislocation and defects introduced [32] because the internal energy introduced by the defects promotes its acceleration.

The elongation to failure of the alloy decreases from an initial value of $35 \%$ to $25 \%$ after the first ECAP passes and then stabilizes up to four passes. After the fourth ECAP pass, the elongation raises till it achieves $30 \%$ after eight ECAP passes. This rise indicates an improvement in the ductility of the studied alloy which can be explained again by the grain refinement and the slight diminution in dislocation density, which in turns can be associated to the increment in the quantity of HAGBs [33]. This decrease can also be explained by recovery and recrystallization, which eliminate dislocations [16].

\subsection{DSC of samples after different ECAP passes}

It can be seen in Figure 11a the DSC curve for the undeformed specimen. It indicates four exothermic peaks and three endothermic peaks. To facilitate reading, the 4 exothermic peaks related to the formation of GP zones and precipitation of $\mathrm{Mg} 2 \mathrm{Si}\left(\beta^{\prime \prime}, \beta^{\prime}\right.$ and $\beta$ ) phases respectively will be referred as event 1 , event 2, event 3 and event 4 (Table 4). The same applies for the endothermic peaks correspond to the dissolution of GP zones, $\beta^{\prime}$ precipitate and $\beta-\mathrm{Mg} 2 \mathrm{Si}$ equilibrium phase, which will be referred to as event 1', event 3' and event 4' (Table 4). This explanation is in agreement with results reported in the literature for similar alloys [34]. 
Figure $11 \mathrm{~b}$ shows the superposition of the DSC curves for the deformed alloy at different ECAP passes. Comparing with the undeformed alloy, several remarks can be extracted regarding the position, intensity and shape of the peaks. The events 1 and 1' corresponding to the formation and the dissolution of GP zones respectively still exist in all deformed specimens. Conversely, the event 2 is apparent in the DSC curves of the alloy after 1, 2 and 3 ECAP passes. The widening of this event (after 1, 2 and 3 ECAP passes) could result from the overlap between the event 3 and the event 4 . This behavior was very similar to a previous work [21] results for an ECAPed AA6060 alloy at room temperature. In comparison with DSC curve for the undeformed specimen, the intensity of this event has reduced and it position has shifted to higher temperatures. The reduction of this event can be due to the partial dissolution of the hardening phase $\beta^{\prime \prime}$. Thus, it can be concluded that after 4 passes, the event 2 is totally suppressed. Figure $11 \mathrm{~b}$ allows to see that event 3 corresponding to the formation of $\beta^{\prime}$ precipitates is missed after 1 , 2 and 3 ECAP passes and it appears after 4, 5, 6 and 8 passes. The lack of the event 3 after the three first ECAP passes may be due to the superposition with the tail of the former event, as other investigations demonstrate [21]. The precipitation sequence is further accelerated compared to the sequence observed at ambient temperature. This acceleration is enhanced by the ECAP temperature and the occurrence of recovery and recrystallization phenomena. A similar result was also observed by Kumar et al. [17] for the same alloy under cryorolling conditions. The events 4 and 4' corresponding to the formation and the dissolution of $\beta-\mathrm{Mg} 2 \mathrm{Si}$ equilibrium phase respectively, still exist in all deformed specimens. In comparison with the undeformed specimen, the intensity of the event 4 has been reduced. According to Khelfa et al. [21] this reduction could be related to the possible Si depletion from the matrix.

The temperature of the event 2 as a function of the ECAP passes number is shown in Figure $11 \mathrm{c}$. It is noticed that this temperature increases slightly $\left(40^{\circ} \mathrm{C}\right)$ from the first ECAP pass and then stabilizes for subsequent numbers. This increase may be correlated with the 
recrystallization process. A slight temperature fluctuation between passes 3 and 5 is observed which can be associated to the rise in HAGBs observed in Figure 4f. A similar variation was also observed in a magnesium ZK60 alloy deformed by ECAP according to Dumitru et al. [33].

Moreover, the decrease in strengths after 2 ECAP passes can be also related to the transformation of metastable $\beta^{\prime \prime}$ precipitates into metastable $\beta^{\prime}$ precipitates, which was confirmed by the DSC results.

\subsection{Stored energy}

Further arguments to the occurrence of softening phenomena can be done by calculating the stored energy. The EBSD results can be used for this purpose. The estimates of the stored local energy can be calculated by the contribution of geometrically necessary dislocations (GNDs) using the Read-Shockley equation [28], as follows:

$$
\gamma(\theta)=\left\{\begin{array}{l}
\left.\gamma_{m} \text { if } \theta_{0}\right\rangle \theta_{m} \\
\gamma_{m}\left(\frac{\theta_{0}}{\theta_{m}}\right)\left[1-\ln \left(\frac{\theta_{0}}{\theta_{m}}\right)\right] \text { if } \theta_{0}\left\langle\theta_{m}\right.
\end{array}\right.
$$

where $\gamma_{\mathrm{m}}=0.324 \mathrm{Jm}^{-2}$ is the value of energy per unit area of HAGB for aluminum [35], $\theta_{0}$ is the value of the boundary misorientation (obtained from the EBSD measurements) and $\theta_{\mathrm{m}}=15^{\circ}$ is the value of the misorientation angle above which the energy per unit area is independent of misorientation angle [28]. The mean boundary energy is obtained as the sum of all the boundary misorientations between $2^{\circ} \leq \theta_{\mathrm{m}} \leq 62.8^{\circ}$ according to the following equation:

$$
\bar{\gamma}=\sum_{2}^{62.8}\left[\gamma\left(\theta_{0}\right) f\left(\theta_{0}\right)\right]
$$

where $f\left(\theta_{0}\right)$ represents the boundary fraction for a given orientation. On the other hand, the stored energy per unit volume attributed to a dislocation boundary $\left(E_{b}\right)$ can be derived by 
multiplying the average energy per unit boundary area $\bar{\gamma}$ with the area per unit volume $\left(S_{V} \approx 2 /\right.$ $d_{E C D}$ where $d_{E C D}$ is the mean equivalent circle diameter considering all misorientations between $2^{\circ} \leq \theta \leq 62.8^{\circ}$. Thus, the stored energy due to the boundary energy $\left(E_{b}\right)$ is given by the next equation:

$$
E_{b}=S_{V} \bar{\gamma}=\frac{2 \bar{\gamma}}{d_{E C D}}
$$

The stored energy from dislocations between cell walls is expressed from the dislocation density measurements applying the next equation [36]:

$$
E_{d}=\frac{1}{2} \rho G b^{2}
$$

where $\mathrm{G}$ is the shear modulus (for Aluminum, $26 \mathrm{GPa}$ ), $\mathrm{b}$ is the length of the Burgers vector of dislocation $(\mathrm{b}=0.286 \mathrm{~nm})$, and $\rho$ is the dislocation density.

Table 5 and Figure 12 summarizes the results of $E_{b}$ and $E_{d}$. The $E_{b}$ rises almost a factor 30 from $0.016 \mathrm{~J} / \mathrm{g}$ to $0.48 \mathrm{~J} / \mathrm{g}$ after 4 ECAP passes, which gives a large driving force for dynamic recrystallization (in accordance with the increment of HAGB fraction from 1 to 4 ECAP passes (Fig.4f)). The $E_{b}$ rises softly from 4 to 8 ECAP passes, showing the slight rise of the driving force. The dependence of $E_{d}$ with the ECAP passes number is displayed in the same figure. It is clearly seen that $E_{d}$ increases from about $3.94 \times 10^{-4} \mathrm{~J} / \mathrm{g}$ to $0.46 \mathrm{~J} / \mathrm{g}$ with increasing ECAP passes from 0 to 2 , and then slightly decreases to about $0.27 \mathrm{~J} / \mathrm{g}$ after eight passes. This decrease can be associated to the dislocation annihilation due to a softening mechanism.

\subsection{Geometrically Necessary Dislocations (GNDs) evolution}

In order to understand the softening observed in the tensile curves with the increase in the number of ECAP passes, the GND evolution was represented in Figure 13. The density of GNDs can be calculated from EBSD data. Figure 13 shows the GND density maps for both the 
undeformed and after different ECAP passes. The initial condition does not exhibit some grouping of GNDs, the GNDs over the scanned area looks quite homogeneous with average and maximum values of $5.1 \cdot 10^{12} \mathrm{~m}^{-2}$ and $5.0 \cdot 10^{13} \mathrm{~m}^{-2}$ respectively. On the other hand, with further ECAP passes the GNDs start to increase and develop places with high densities. This behavior is also corroborated by the GNDs distributions in Figure 13 which show a shifting in the peaks to higher values.

After one and two ECAP passes the average GND values were $3 \cdot 10^{13} \mathrm{~m}^{-2}$ and $9 \cdot 10^{13} \mathrm{~m}^{-2}$ reaching maximum values of $1.5 \cdot 10^{14} \mathrm{~m}^{-2}$ and $2.5 \cdot 10^{14} \mathrm{~m}^{-2}$ respectively. These increments correspond well with the energy calculations coming from the grain boundaries showed before in the section 3.7 which also presented and increasing behavior with the deformation. After four, six and eight ECAP passes the average GND values start to reach a saturation with values of $1.2 \cdot 10^{14}, 1.3 \cdot 10^{14}$ and $1,5 \cdot 10^{14} \mathrm{~m}^{-2}$ respectively.

GNDs as a precursor of grain subdivision tends to show a decreasing behavior with higher deformations as has been indicated by Tóth et al.[37]. However, in this study a continuous increasing behavior was found which could be attributed to the ECAP processing conditions (temperature) that generates a recovery state in the microstructure given rise to a lot of potential places for the grain subdivision. For that reason, while the GND values increase with deformation, the dislocations calculated by the X-ray decrease after the second ECAP pass. The values of GNDs reported in other studies such as accumulative roll bonding (ARB) [38] ECAP [39] and HPT [40] presented higher magnitudes than the values reported in this study. Those differences can be related to different factors like the higher amount of deformation introduced, the processing conditions (room temperature) and the hydrostatic pressures involved in these processes, especially in HPT. As established by Tóth et al. [39], the higher hydrostatic pressures favored the dislocation multiplication instead of their annihilation. 


\section{Conclusions}

During the present work, the following conclusions can be drawn:

- The results reveal a successful strategy for processing the AA6082 by ECAP up to eight passes at $250^{\circ} \mathrm{C}$. It is seen that pressing may be conducted without sample segmentation and cracking. - After the first ECAP pass, the alloy has a microstructure consisting of elongated grains with a large amount of LAGBs, associated with the formation of sub-grains. By rising the ECAP passes number, LAGBs were progressively transformed to HAGBs. The fraction of HAGBs was raised from $\sim 22.1 \%$ after one ECAP pass to $\sim 57 \%$ after eight ECAP passes.

- The dislocation density and the lattice strain rise in the early ECAP stage but continuously decrease after 2 ECAP passes. This diminution may be interpreted in terms of the occurrence of continuous recovery and dynamic recrystallization.

- After the two first passes the texture is dominated by the shearing components. By increasing the ECAP passes number, the material texture changed from shear components to be dominated by recrystallization texture components. This change can be due to the occurrence of recovery and recrystallization phenomena.

- An increase of YS was observed after one ECAP pass, and then diminish until 8 ECAP passes. The rise of the YS can be due to intensive dislocation density in the first ECAP pass. Diminution is also associated to the concurrent softening phenomena.

- The calculated stored energy rises abruptly to a value of $0.48 \mathrm{~J} / \mathrm{g}$ after 4 passes and then it rises slight from 4 to 8 ECAP passes around a value of $0.62 \mathrm{~J} / \mathrm{g}$. However, the dislocations energy rises with rising ECAP passes and reaches a maximum after 2 ECAP passes, when the stored energy is $0.46 \mathrm{~J} / \mathrm{g}$ and $\mathrm{t}$ then starts to diminish at increasing ECAP passes.

- During first ECAP passes, a significant increase in GND density is produced to reach a stable state rapidly. This stabilization can be attributed to the state of dynamic equilibrium reached between multiplication and annihilation of dislocations. On the other hand, the dislocations 
calculated by the X-ray showed a decrease after the second ECAP pass that was attributed to a kind of softening as a consequence of dislocation annihilation.

- Severe plastic deformation under this processing conditions for the AA6082 alloy demonstrated not to be an efficient tool to improve the mechanical properties due to the occurrence of recovery and recrystallization phenomena, which was corroborated by the texture evolution, dislocation densities and mechanical properties. Where 2 ECAP passes demonstrated to be the maximum deformation to show some improve with the material properties.

\section{Acknowledgements}

The authors would like to thank Fundación CTM (Centro Tecnológico de Manresa) for their support with the DSC analysis.

\section{References}

[1] R.Z. Valiev, T.G. Langdon, Principles of equal-channel angular pressing as a processing tool for grain refinement. Prog. Mater. Sci. 51, 881-981 (2006)

[2] K.Nakashima, Z.Horita, M.Nemoto, T.G.Langdon, Influence of channel angle on the development of ultrafine grains in equal-channel angular pressing. Acta.Mater.46, 1589-1599 (1998)

[3] X. Zhao, X. Yang, X. Liu, C.T. Wang, Y. Huang, T.G. Langdon, Processing of commercial purity titanium by ECAP using a 90 degrees die at room temperature Mater. Sci. Eng.A, 607, 482-489 (2014)

[4] Y.Han, J. Li, G. Huang, Y. Lv, X. Shao, W. Lu, D. Zhang, Effect of ECAP numbers on microstructure and properties of titanium matrix composite Mater. Des. 75, 113-119 (2015)

[5] Z. Horita, T. Fujinami, M. Nemoto, T.G. Langdon, Improvement of mechanical properties for Al alloys using equal-channel angular pressing. J.Mater.Process.Technol. 117, 288-292 (2001) 
[6] Z. Lee, R. Rodriguez, R.W. Hayes, E.J. Lavernia, S.R. Nutt, Microstructural Evolution and Deformation of Cryomilled Nanocrystalline Al-Ti-Cu Alloy. Metall. Mater. Trans. A 34, 1473$1481(2003)$

[7] M.r. Baig, E. El-Danaf, J.A. Mohammad, Thermo-mechanical responses of an aluminum alloy processed by equal channel angular pressing. Mater.Des. 57, 510-519 (2014)

[8] M.H. Shaeri, M.T. Salehi, S.H. Seyyedein, M.R. Abutalebi, J.K. Park, Microstructure and mechanical properties of Al-7075 alloy processed by equal channel angular pressing combined with aging treatment. Mater. Des. 57, 250-257 (2014)

[9] P. Cetlin, M. Aguilar, R. Figueiredo, T. Langdon, Avoiding cracks and inhomogeneities in billets processed by ECAP. J. Mater. Sci. 45, 4561-4570 (2010)

[10] N.Q. Chinh , J. Gubicza T. Czeppec, J. Lendvai, C. Ruslan, Z.Valiev, T. G. Langdon, Developing a strategy for the processing of age-hardenable alloys by ECAP at room temperature. Mater. Sci. Eng. A. 516, 248-252 (2009)

[11] C.M. Cepeda-Jiménez. J.M. García-Infanta, O.A Ruano, F. Carreño, Mechanical properties at room temperature of an $\mathrm{Al}-\mathrm{Zn}-\mathrm{Mg}-\mathrm{Cu}$ alloy processed by equal channel angular pressing. $\mathrm{J}$. Alloys. Compd. 509, 8649-8656 (2011)

[12] Y. Iwahashi, J. Wang, M. Horita, M. Nemoto, T.G. Langdon, Principle of equal-channel angular pressing for the processing of ultra-fine grained materials. Scr. Mater. 35, 143-146 (1996) [13] M.H. Shaeri, M. Shaeri, M.T. Salehi, S.H. Seyyedein, M.R. Abutalebi, Effect of equal channel angular pressing on aging treatment of Al-7075 alloy. Prog.Nat.Sci.Mater.Int. 25, 159$168(2015)$

[14] Y.J. Chen, Y.C. Chai, H.J. Roven, S.S. Gireesh,Y.D. Yu, J. Hjelen, Microstructure and mechanical properties of $\mathrm{Al}-\mathrm{xMg}$ alloys processed by room temperature ECAP. Mater. Sci. Eng. A. $545,139-147$ (2012) 
[15] M. Dehghan, F. Qods, M. Gerdooe,i Investigation of Microstructure of the Commercial Pure Aluminium in the ARB Process. Mater. Sci. Forum. 702-703, 147-150 (2012)

[16] N. Kumar, S. Goel, R.Jayaganthan, H;G; Brokmeier, Effect of grain boundary misorientaton, deformation temperature and AlFeMnSi-phase on fatigue life of $6082 \mathrm{Al}$ alloy. Mater. Charact. 124, 229-240 (2017)

[17] N. Kumar, P. Nageshwara Rao, R. Jayaganthan, Heinz-Günter Brokmeier, Effect of cryorolling and annealing on recovery, recrystallisation, grain growth and their influence on mechanical and corrosion behaviour of $6082 \mathrm{Al}$ alloy. Mater Chem.Phys. 165, 177-187 (2015)

[18] I.J. Beyerlein, L. S. Tóth, Texture evolution in equal-channel angular extrusion. Prog. Mater. Sci. 54, 427-510 (2009)

[19] J.K. Mackenzie, Second paper on statistics associated with the random disorientation of cubes. Biometrika. 45, 229-240 (1958)

[20] S. Subbarayan, H. J. Roven, Y. J. Chen, P. C. Skaret, Microstructure evolution in pure aluminium processed by equal channel angular pressing at elevated temperature. Int. J. Mater.Res. 104, 630-636 (2013)

[21] T. Khelfa, M. A. Rekik, M. Khitouni, J. M. Cabrera-Marrero, Structure and microstructure evolution of $\mathrm{Al}-\mathrm{Mg}-\mathrm{Si}$ alloy processed by equal-channel angular pressing. Int.J.Adv.Man. Technol.92, 1731-1740 (2017)

[22] I. Mazurina, T. Sakai, H. Miura, O. Sitdikov, R. Kaibyshev, Grain refinement in aluminum alloy 2219 during ECAP at $250^{\circ}$ C. Mater. Sci. Eng. A. 473, 297-305 (2008)

[23] N. Gao, M.J. Starink, M. Furukawa, Z. Horita, C. Xu, T.G. Langdon, Microstructural evolution in a spray-cast aluminum alloy during equal-channel angular pressing. Mater.Sci. Eng. A. $410-411,303-307(2005)$

[24] N. Gao, M.J. Starink, M. Furukawa, Z. Horita, C. Xu, T.G. Langdon, Nanomaterials by Severe Plastic Deformation. (Trans Tech Publications Ltd, Zurich-Uetikon, 2006), pp.275-280 
[25] S.K. Panigrahi, R. Jayaganthan, A study on the mechanical properties of cryorolled AlMg Si alloy. Mater.Sci.Eng.A, 480, 299-305 (2008)

[26] J.I. Langford, A rapid method for analysing the breadths of diffraction and spectral lines using the Voigt function. Appl Cryst 11, 10-14 (1978)

[27] R.Z. Valiev, M.Y. Murashkin, A.V. Ganeev, Superstrength of nanostructured metals and alloys produced by severe plastic deformation. Phys.Met.Metallogr. 113, 1193-1201 (2012)

[28] F. Humphreys, M. Hatherly, Recrystallization and related annealing phenomena, (Pergamon Press, Oxford, United Kingdom, 1996)

[29] L. Zhang, Y. Wang, X. Yang, K. Li, S. Ni, Y. Du, M. Song, Texture, microstructure and mechanical properties of 6111 aluminum alloy subject to rolling deformation. Mater.Res. 20, 1360- $1368(2017)$

[30] S. Wronski, J. Tarasiuk, B. Bacroix, K. Wierzbanowski, H. Paul, Microstructure heterogeneity after the ECAP process and its influence on recrystallization in aluminium. Mater.charact. 78, 60-68 (2013)

[31] J. A. Muñoz Bolaños, O. F. Higuera Cobos, V. Tartalini, P. Risso, M. Avalos, R. E. Bolmaro, Inducing heterogeneity in an austenitic stainless steel by equal channel angular sheet extrusion (ECASE). Int J Adv Manuf Technol. 1, 2473-2479 (2019)

[32] D. Setman, E. Schafler, E. Korznikova, M.J. Zehetbauer, The presence and nature of vacancy type defects in nanometals detained by severe plastic deformation. Mater. Sci. Eng. A 493, 116$122(2008)$

[33] F.D. Dumitru, O.F. Higuera-Cobos, J.M. Cabrera, ZK60 alloy processed by ECAP: Microstructural, physical and mechanical characterization. Mater.Sci.Eng.A 594,32-39 (2014)

[34] Y. Birol, DSC analysis of the precipitation reactions in the alloy AA6082. J.Therm.Anal. Calorim. 83, 219-222 (2006) 
[35] N. Kamikawa, X. Huang, Y.Kondo, T. Furuhara, N. Hansen, Stored Energy and Annealing Behavior of Heavily Deformed Aluminium. Mater. Sci.Forum, 715-716, 367-372 (2012)

[36] F.J. Humphreys, M. Hatherly, Recrystallization and Related Annealing Phenomena, 2nd edn.( Pergamon Press, Oxford, 2004)

[37] L. S. Toth, C. F. Gu, B. Beausir, J. J. Fundenberger, M. Hoffman, Geometrically necessary dislocations favor the Taylor uniform deformation mode in ultra-fine-grained polycrystals. Acta.Mater. 117, 35-42 (2016)

[38] F. Cruz-Gandarilla, A. M. Salcedo-Garrido, R. E. Bolmaro, T. Baudin, N. S. De Vincentis, M. Avalos, J. G. Cabañas-Moreno, H. Mendoza-Leon. Microstructural evolution and mechanical properties on an ARB processed IF steel studied by X-ray diffraction and EBSD Mater. Charact. $118,332-339(2016)$

[39] L. Tóth, C. Gu, Ultrafine-grain metals by severe plastic deformation. Mater Charact. 92, 1$14(2014)$

[40] A. Pougis, L. S. Toth, J. J. Fundenberger, A. Borbely, Extension of the Derby relation to metals severely deformed to their steady-state ultrafine-grain size. Scr.Mater. 72, 59-62 (2014) 
Cracks of AA6082
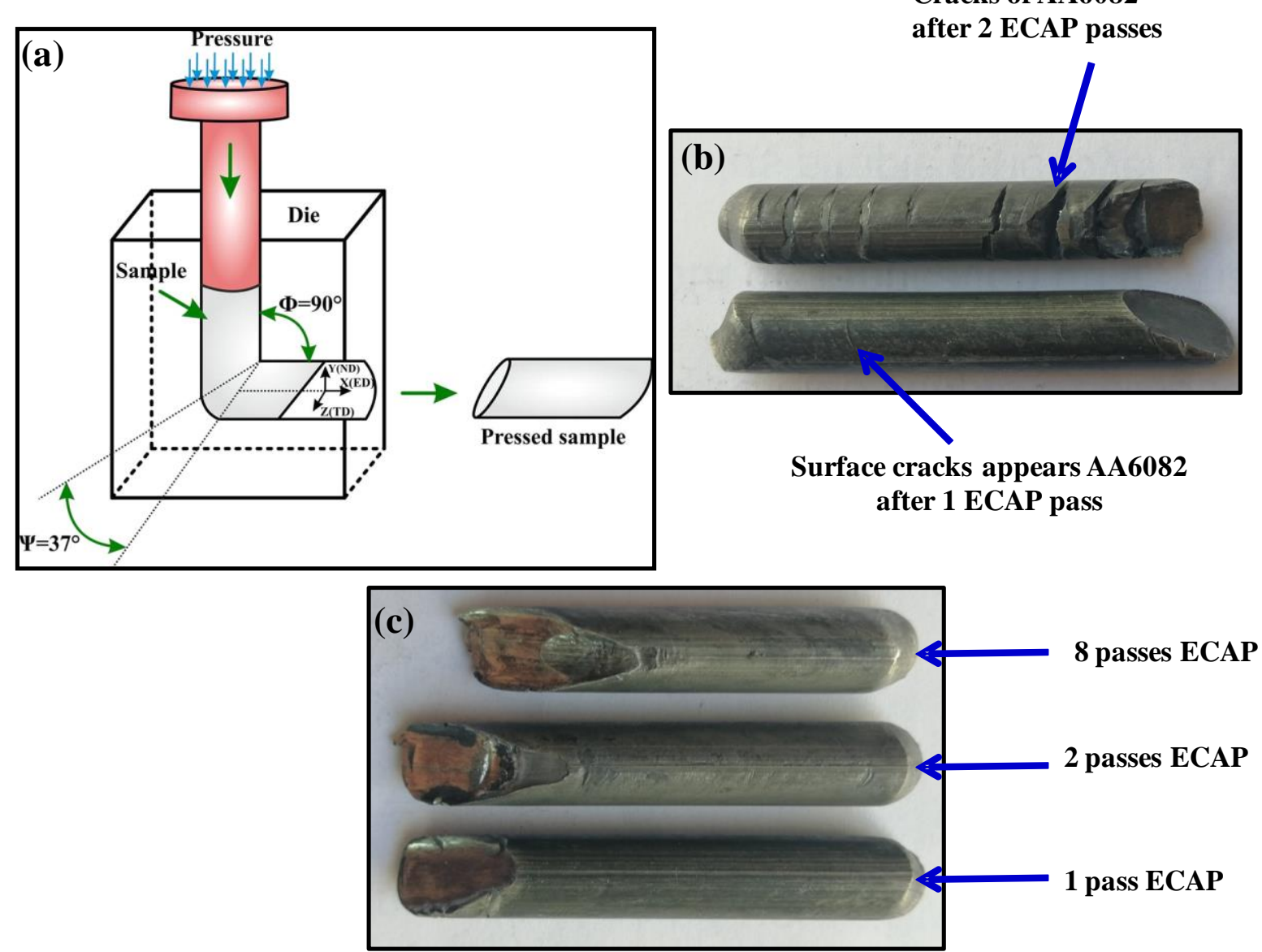

Fig.1. a) Schematic illustration of the ECAP process, b) Surface cracks of the ST AA6082 subjected to ECAP processing for 1 and 2 passes at room temperature and c) Surface without cracks of the ST AA6082 subjected to ECAP processing for 1 to 8 passes at warm temperature 

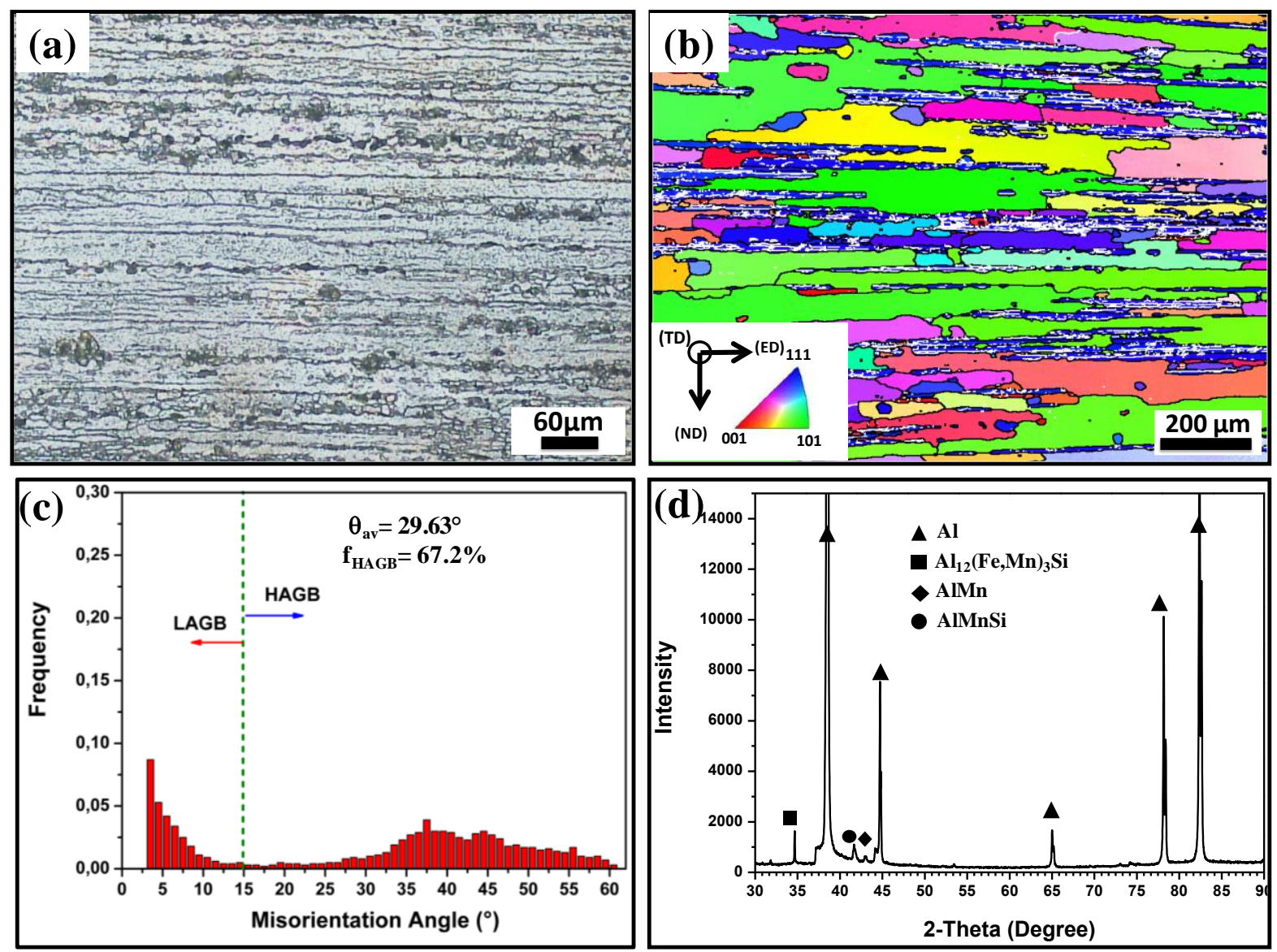

Fig.2. Initial microstructure of AA6082 aluminum alloy before ECAP after ST: (a) optical micrograph, (b) typical EBSD map, (c) misorientation angle distribution, and (d) typical XRD pattern. 


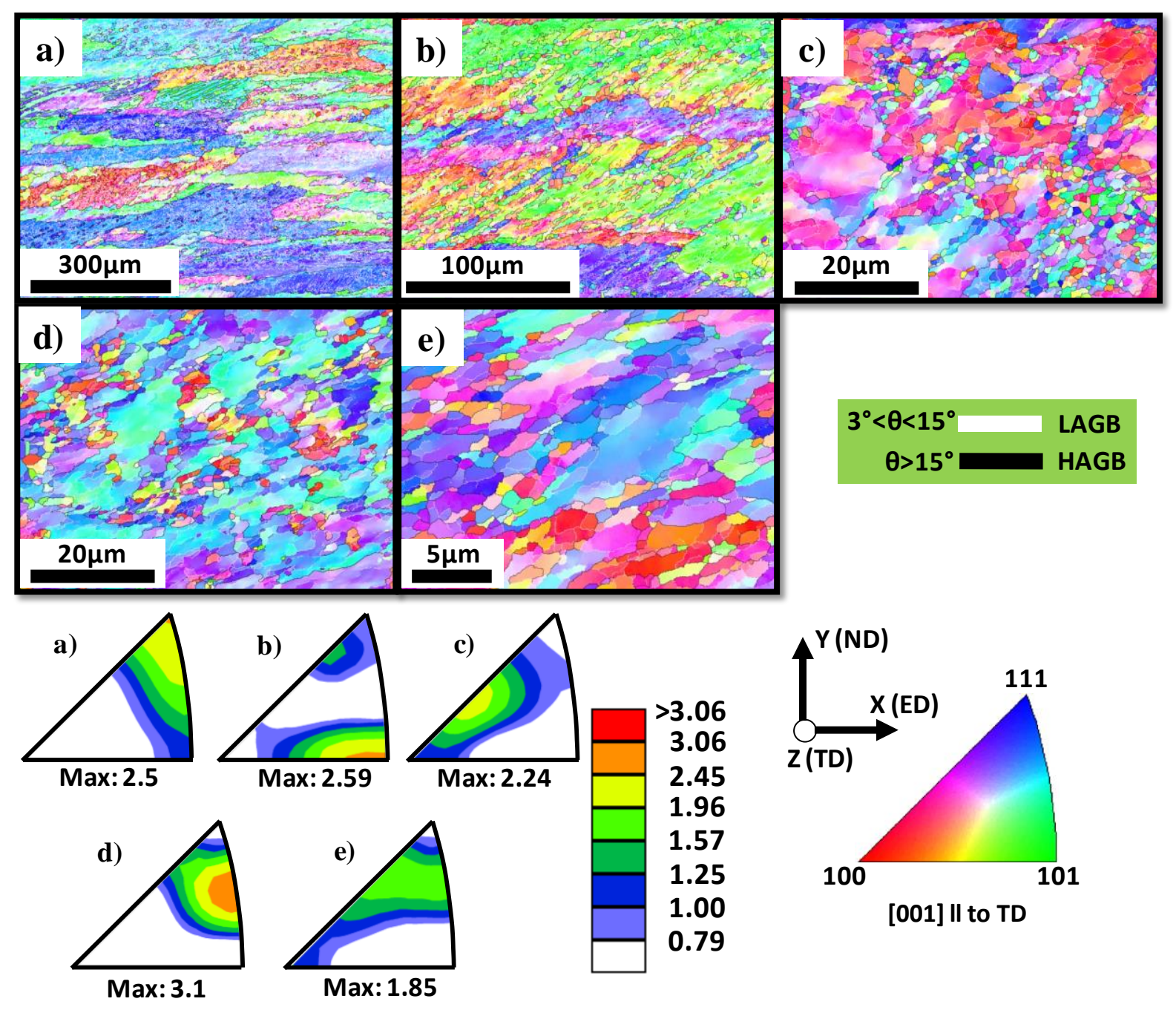

Fig.3. EBSD maps and inverse pole figures of AA6082 processed by ECAP with different number of passes: a) 1 pass, b) 2 passes, c) 4 passes, d) 6 passes and e) 8 passes. 

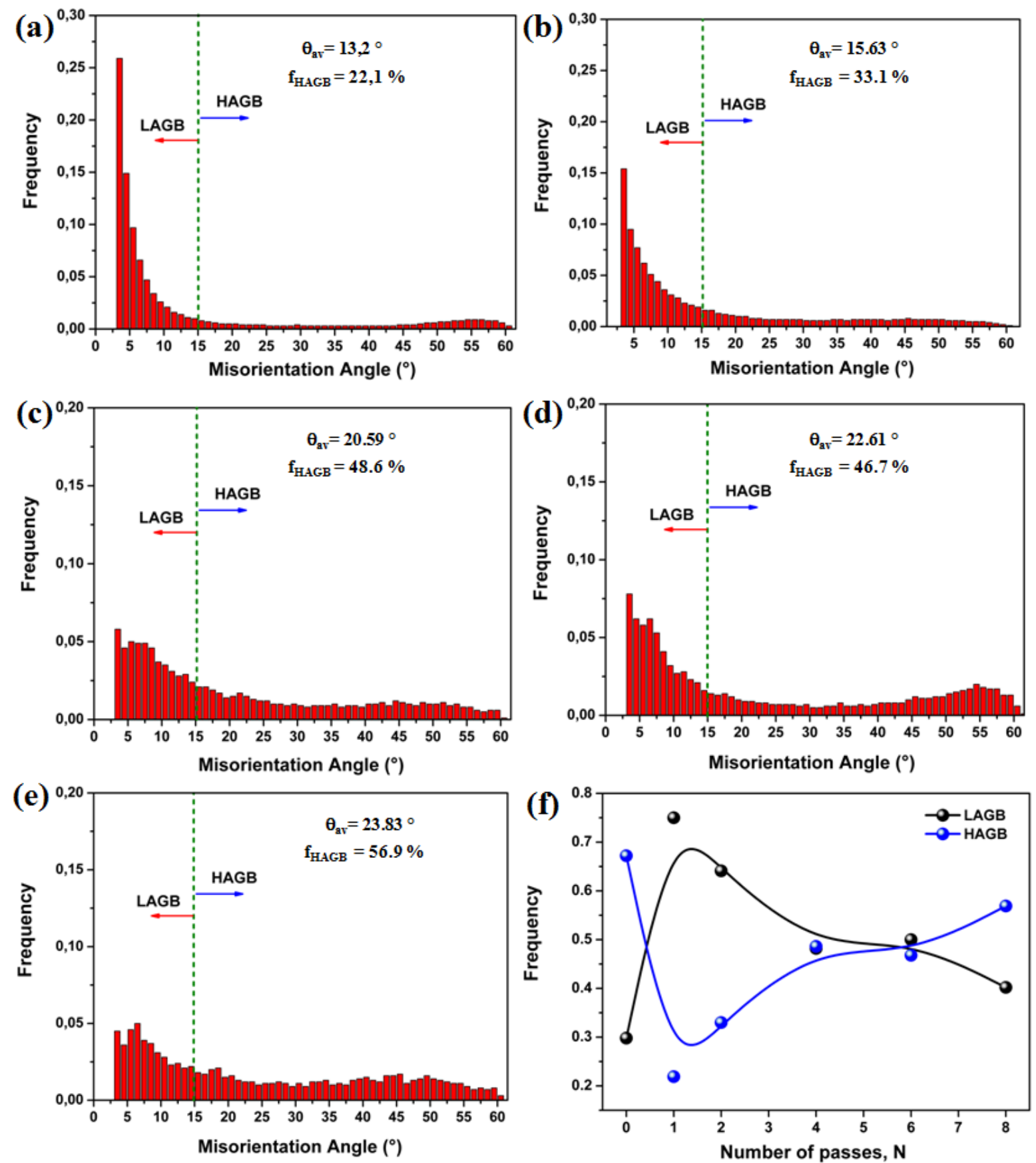

Fig.4. The misorientation distributions of AA6082 processed by ECAP with different passes: (a) 1 pass, (b) 2 passes, (c) 4 passes, (d) 6passes and (e) 8 passes, (f) Dependence of the amount of HAGB and LAGB 


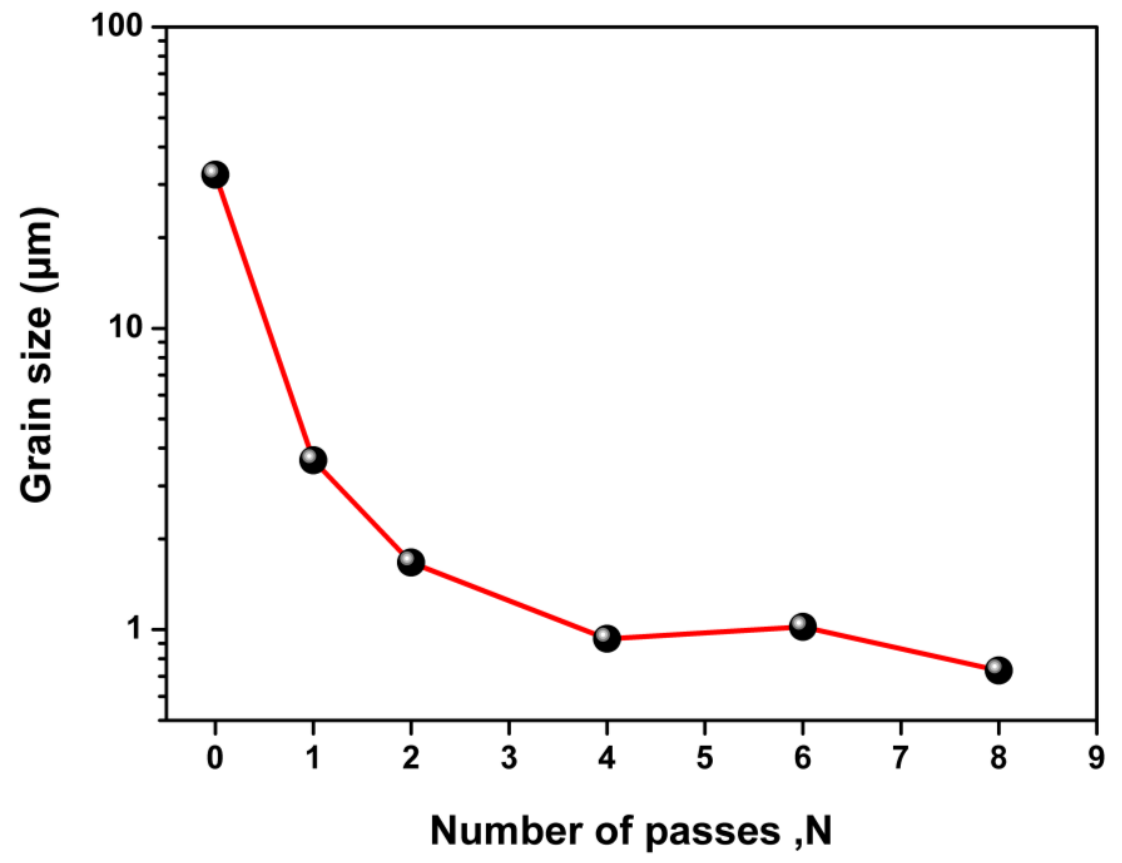

Fig. 5. Dependence of the grain size on the ECAP passes number at $250^{\circ} \mathrm{C}$.

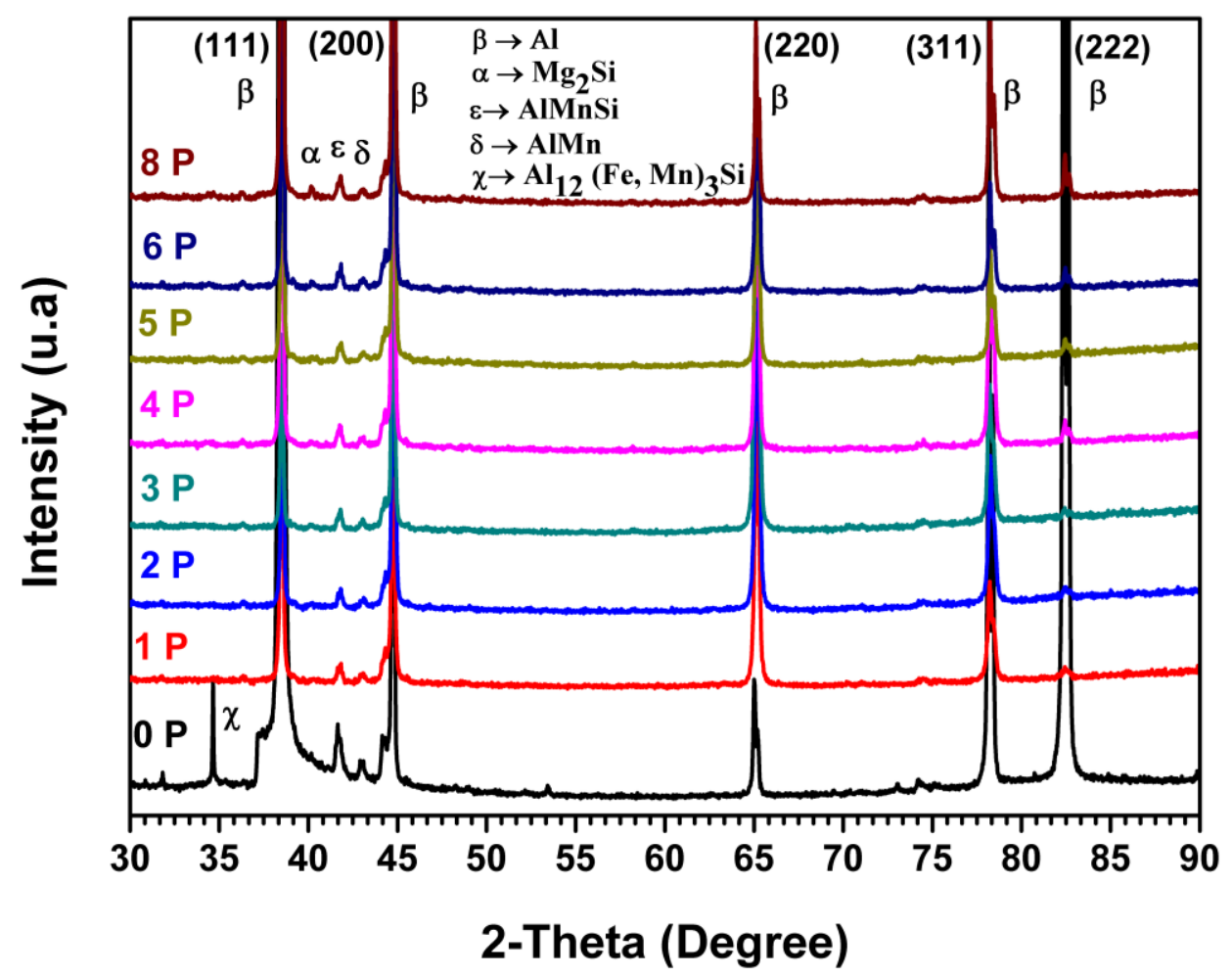

Fig.6. X-ray diffraction patterns of AA6082 before and after different ECAP passes. 

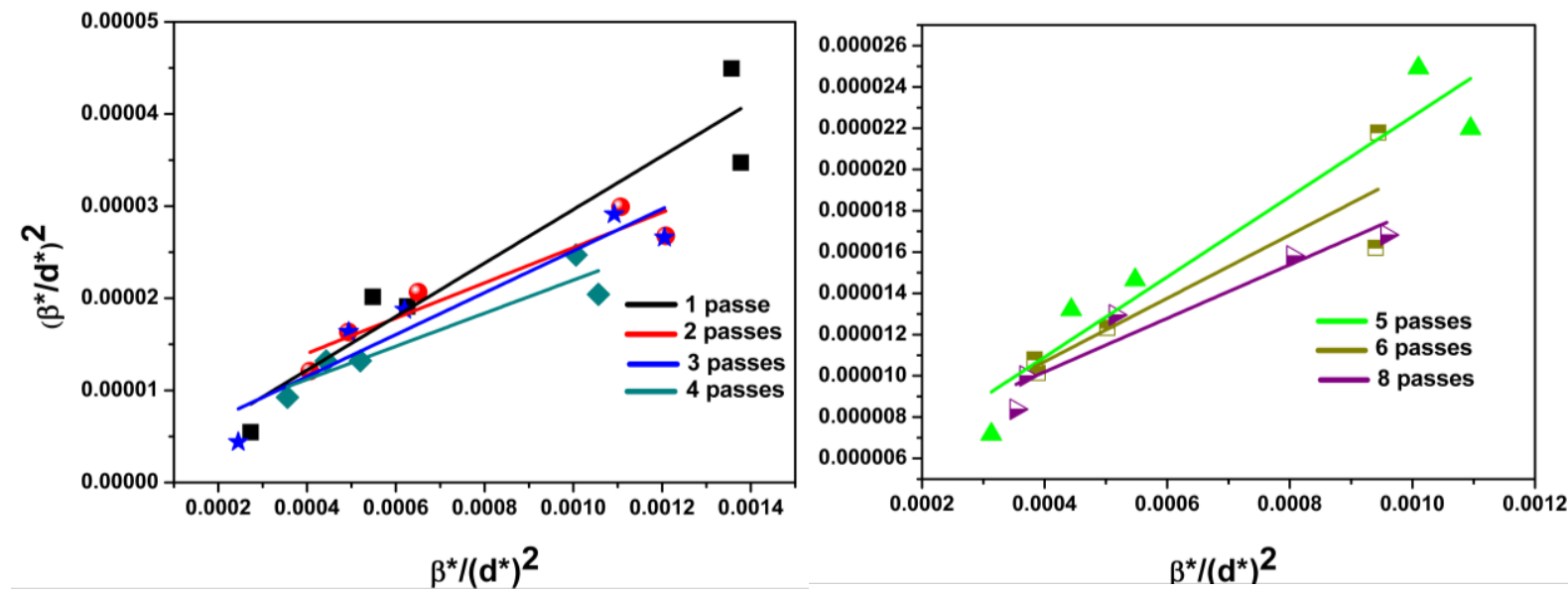

Fig. 7. Halder-Wagner plots of AA6082 at different ECAP passes. 


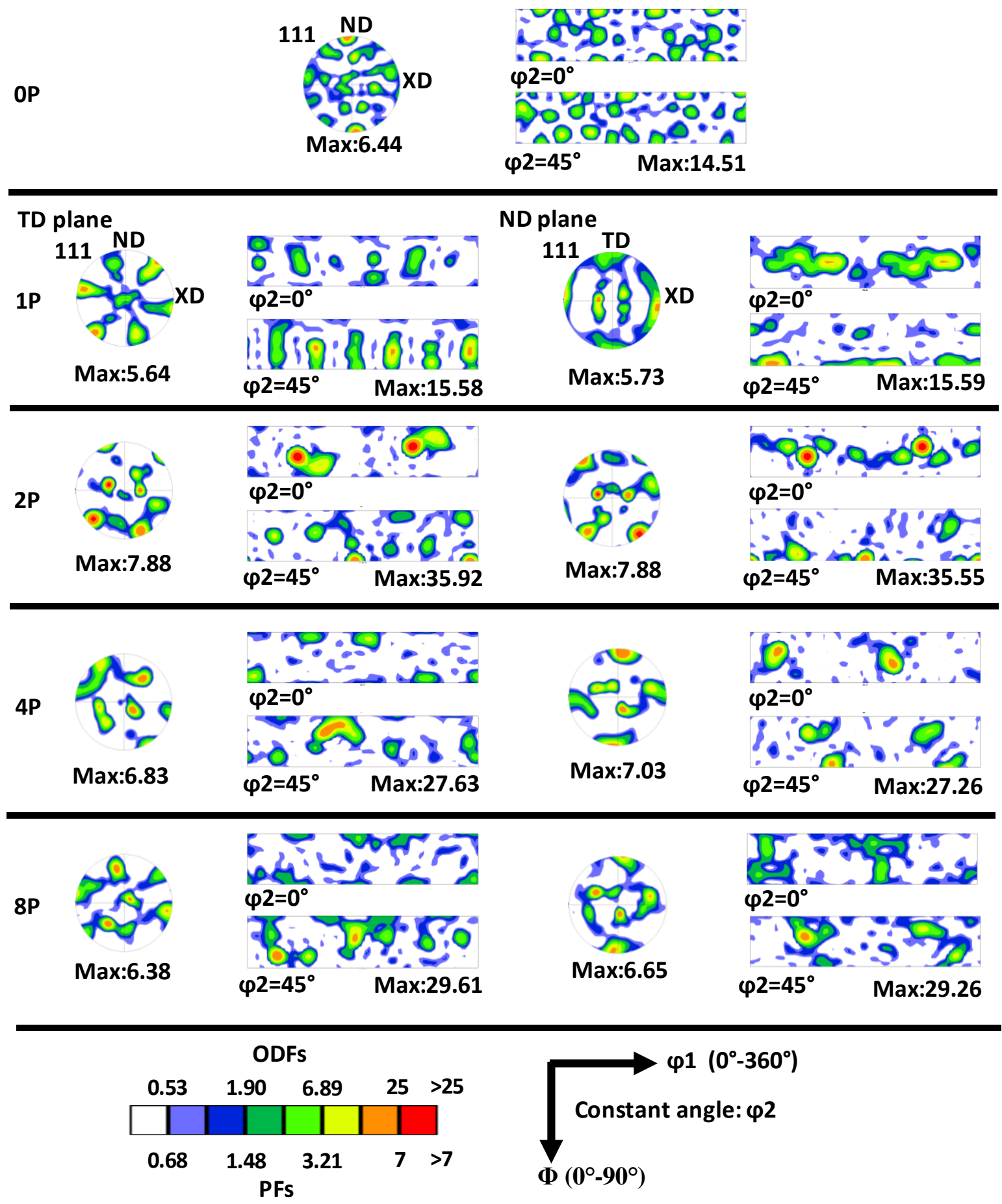

Fig. 8 Texture evolution representation by Pole Figures (PFs) and Orientation Distribution Functions (ODFs) at different number of ECAP passes over the TD and the ND planes. 


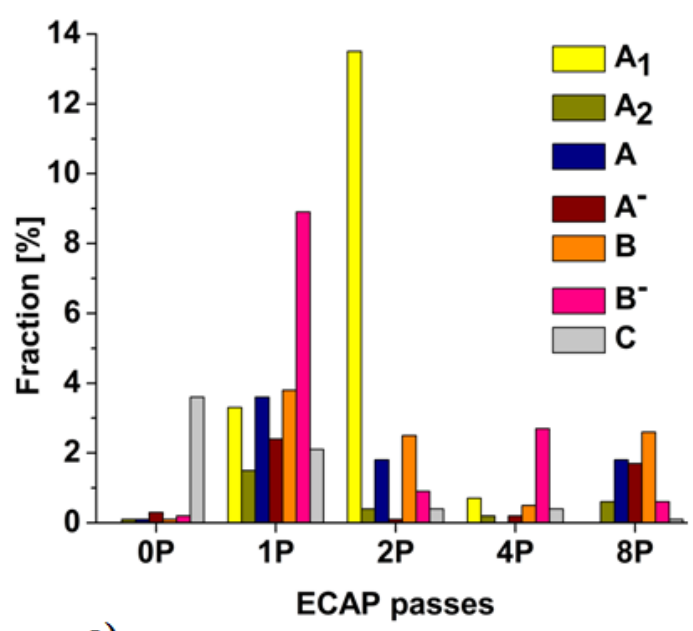

a)

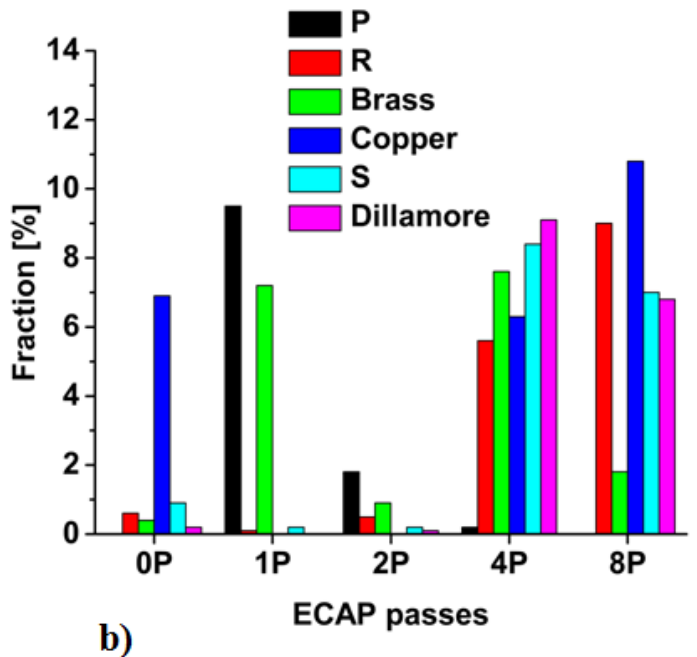

b)

Fig.9. Texture components evolution at different number of ECAP passes, a) ECAP components and b) recrystallization components.

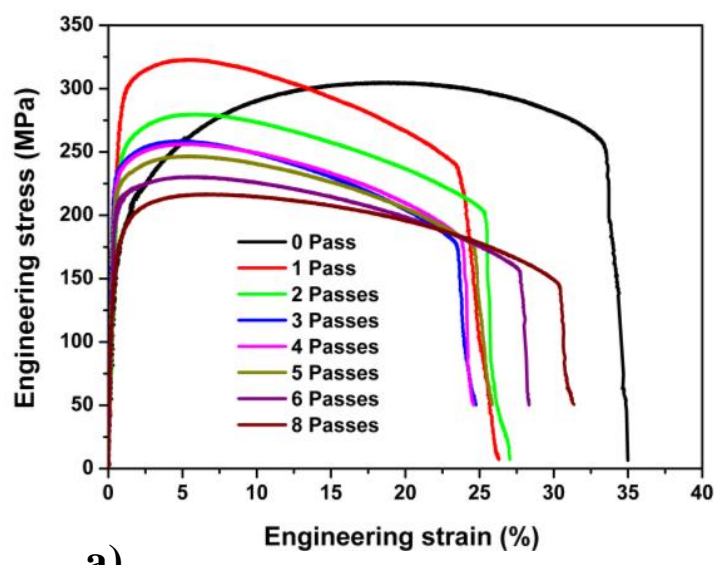

a)

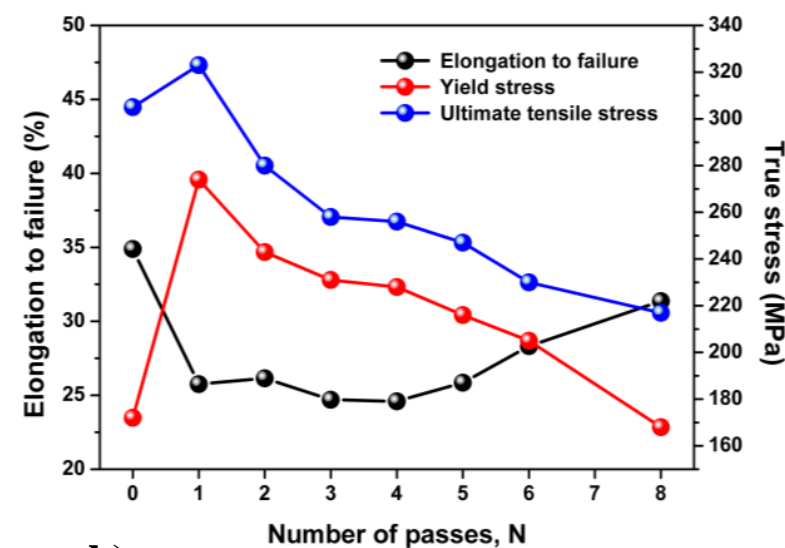

b)

Fig.10. a) Engineering stress-strain curves and b) yield stress, UTS and elongation to failure of AA6082 at different ECAP passes. 


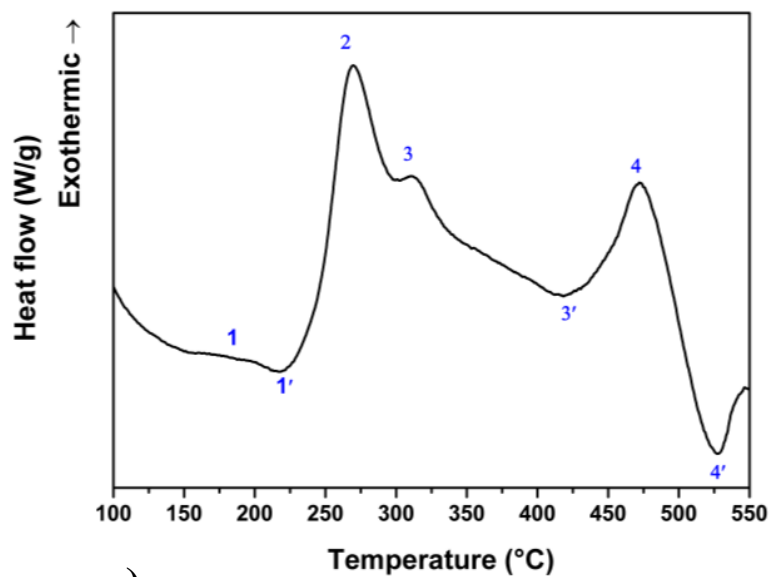

a)

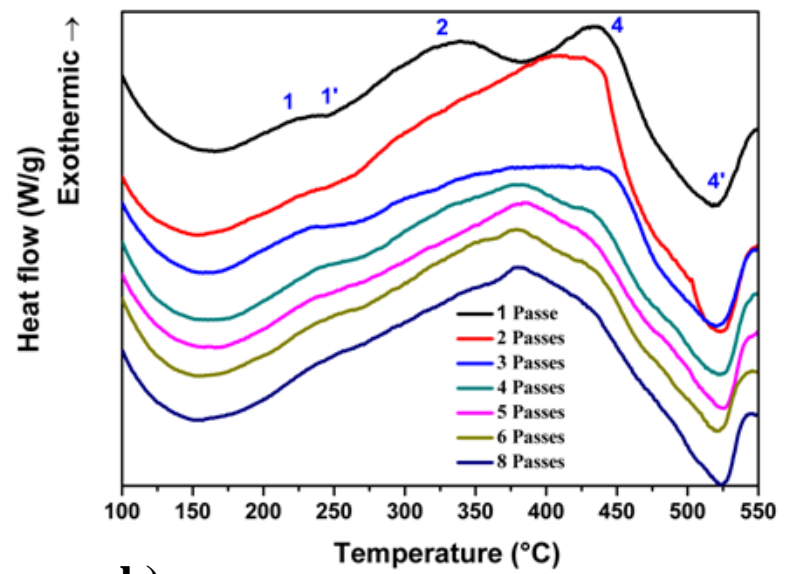

b)

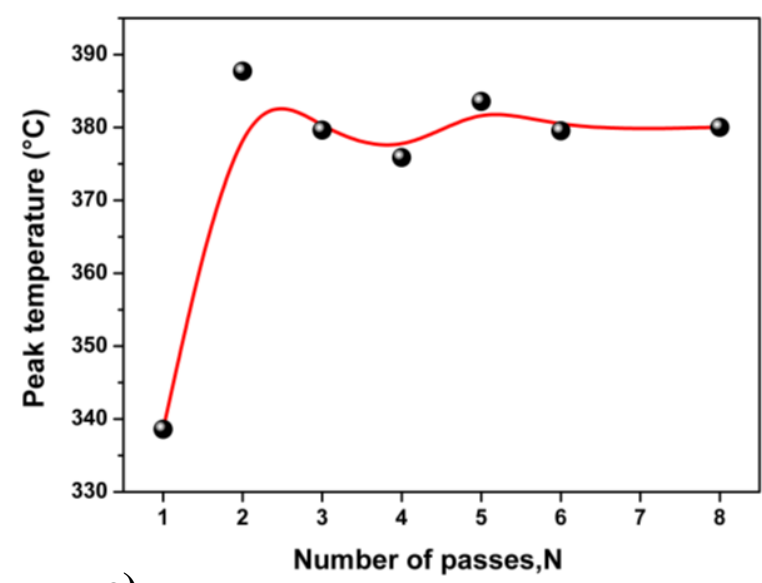

c)

Fig.11. DSC plot of as-received and ECAPed $6082 \mathrm{Al}$ alloy at different passes, a) Starting ST, b) ECAPed material at different ECAP passes and c) Dependence of the peak $\beta$ 'on the number of ECAP passes. 


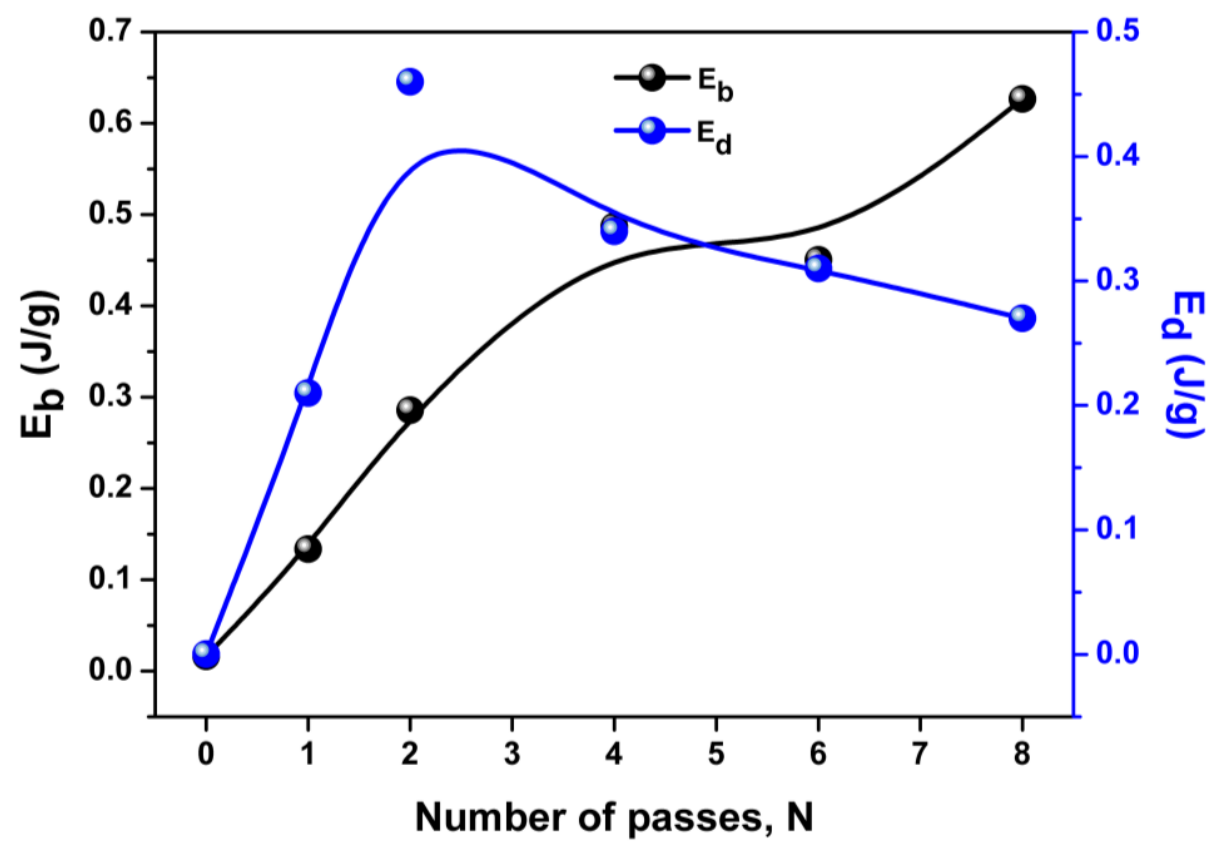

Fig.12. Boundary energy of the present alloy and dislocation energy as a function of the ECAP passes number. 

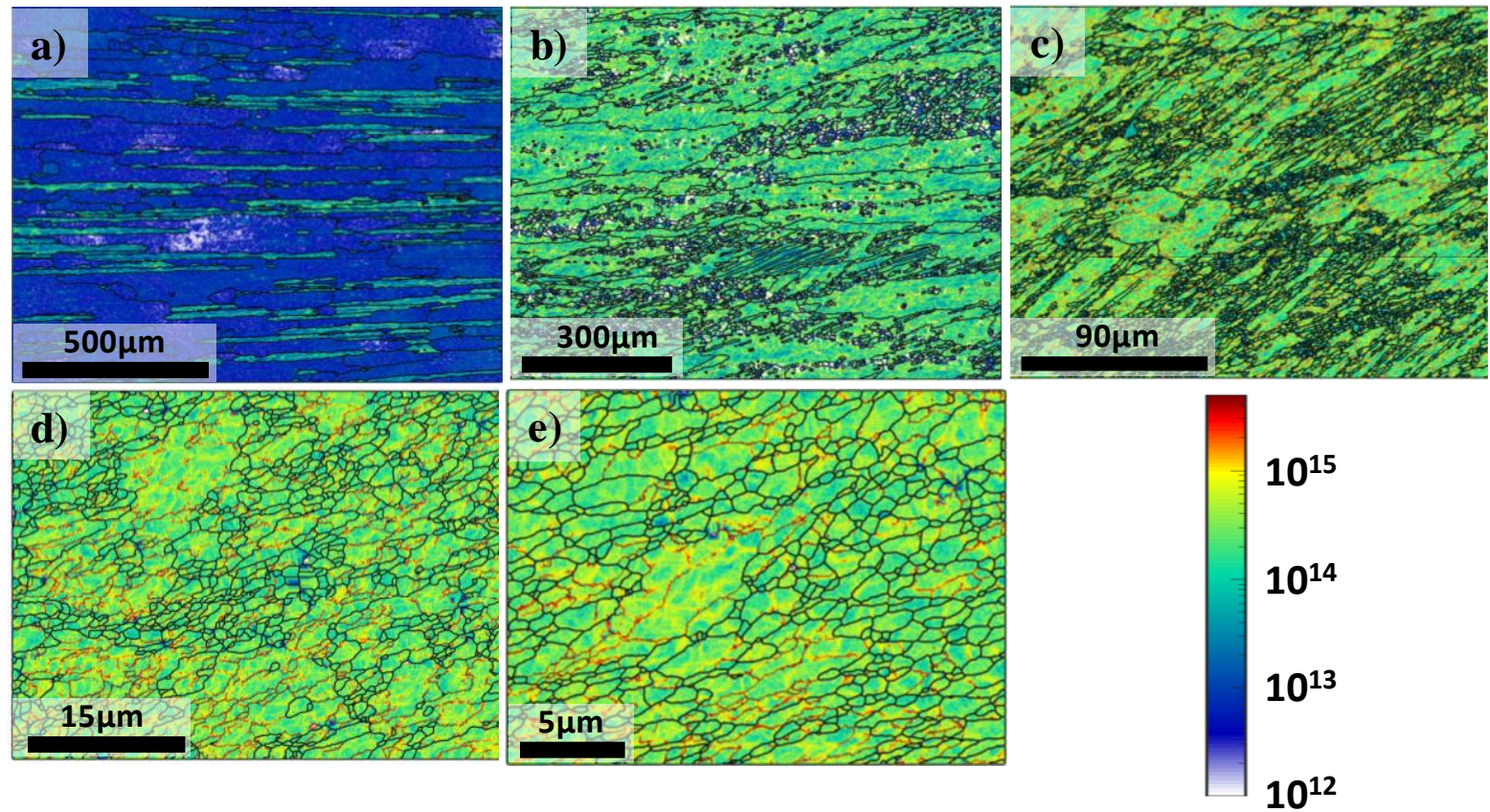

\section{HAGB}

$\theta>15^{\circ}$

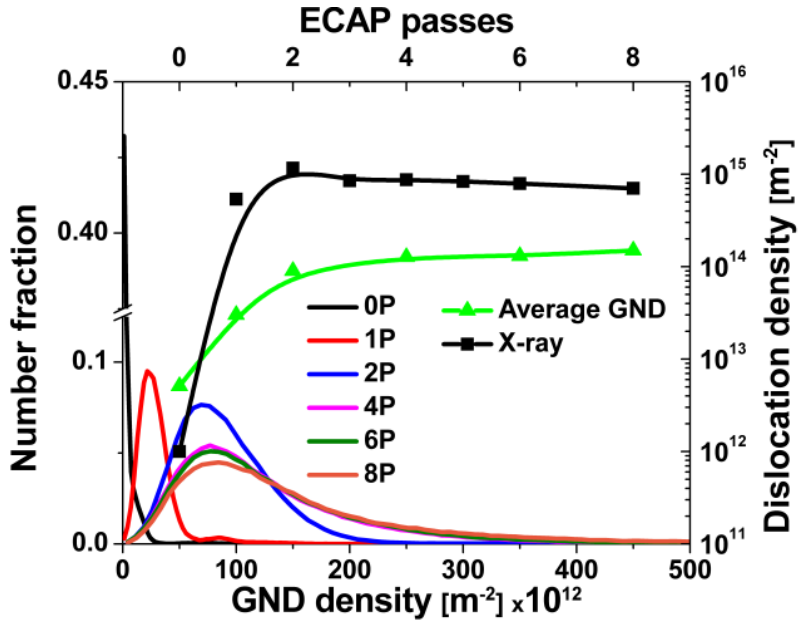

Fig.13. GNDs evolution for the AA6082 before and after ECAP processing. 
Table 1. Chemical composition of AA6082 (in \%wt).

\begin{tabular}{clcccc}
\hline Element & wt\% & Element & wt\% & Element & wt\% \\
\hline $\mathrm{Al}$ & 96.5 & $\mathrm{Ca}$ & 0.0025 & $\mathrm{Zn}$ & 0.1625 \\
$\mathrm{~V}$ & 0.0066 & $\mathrm{Ti}$ & 0.0321 & $\mathrm{Mg}$ & 0.841 \\
$\mathrm{Sr}$ & 0.0004 & $\mathrm{Sn}$ & 0.0027 & $\mathrm{Mn}$ & 0.829 \\
$\mathrm{Sb}$ & 0.1750 & $\mathrm{~Pb}$ & 0.0217 & $\mathrm{Cu}$ & 0.1071 \\
$\mathrm{P}$ & 0.0013 & $\mathrm{Cr}$ & 0.0222 & $\mathrm{Fe}$ & 0.3931 \\
$\mathrm{Na}$ & 0.0007 & $\mathrm{Ni}$ & 0.0167 & $\mathrm{Si}$ & 0.863 \\
\hline
\end{tabular}

Table 2. Structural parameters and dislocation density of the AA6082 alloy processed by ECAP.

\begin{tabular}{cccc}
\hline ECAP passes & DXRD $(\mathbf{n m})$ & $\left\langle\varepsilon^{\mathbf{2}}\right\rangle^{\mathbf{1} / \mathbf{2}}(\boldsymbol{\%})$ & $\boldsymbol{\rho}\left(\mathbf{1 0}^{\mathbf{1 4}}\right) \mathbf{~ m}^{-\mathbf{2}}$ \\
\hline 1 & 34 & 0.15 & 5.36 \\
2 & 52 & 0.50 & 11.67 \\
3 & 44 & 0.31 & 8.54 \\
4 & 56 & 0.40 & 8.69 \\
5 & 51 & 0.35 & 8.32 \\
6 & 65 & 0.42 & 7.91 \\
8 & 77 & 0.44 & 7.01 \\
\hline
\end{tabular}


Table 3. ECAP and recrystallization texture components fcc materials [28].

\begin{tabular}{|c|c|c|c|c|c|}
\hline \multirow[t]{2}{*}{ Texture component } & \multirow{2}{*}{$\begin{array}{c}\text { Miller indices } \\
\{\text { hkl }\}<u v w>\end{array}$} & \multicolumn{3}{|c|}{ Euler angles } & \multirow{15}{*}{ 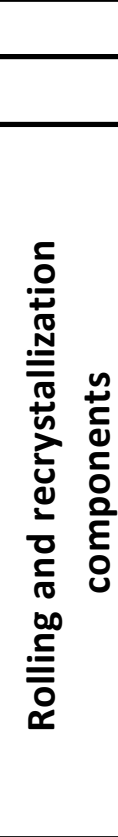 } \\
\hline & & $\varphi_{1}$ & $\varphi$ & $\varphi_{2}$ & \\
\hline Cube & $\{001\}<100>$ & 0 & 0 & 0 & \\
\hline $\mathrm{P}$ & $\{011\}<122>$ & 70 & 45 & 0 & \\
\hline $\mathrm{R}$ & $\{124\}<211>$ & 57 & 29 & 63 & \\
\hline Goss & $\{011\}<100>$ & 0 & 45 & 0 & \\
\hline$S$ & $\{123\}<634>$ & 59 & 37 & 63 & \\
\hline Rotated goss & $\{011\}<011>$ & 90 & 45 & 0 & \\
\hline Brass & $\{011\}<211>$ & 35 & 45 & 0 & \\
\hline Goss/brass & $\{011\}<115>$ & 16 & 45 & 0 & \\
\hline Y & $\{111\}<112>$ & 90 & 55 & 45 & \\
\hline Copper & $\{112\}<111>$ & 90 & 35 & 45 & \\
\hline Rotated copper & $\{112\}<011>$ & 0 & 35 & 45 & \\
\hline Dillamor & $\{4411\}<11118>$ & 90 & 27 & 45 & \\
\hline S/brass & $\{414\}<234>$ & 49 & 40 & 75 & \\
\hline \multirow[t]{2}{*}{$\mathrm{A}_{1} *$} & \multirow[t]{2}{*}{$(81 \overline{1})[1 \overline{4} 4]$} & 80.26 & 45 & 0 & \multirow{9}{*}{ 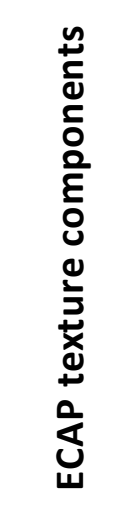 } \\
\hline & & 170.26 & 90 & 45 & \\
\hline \multirow[t]{2}{*}{$\mathrm{A}_{2} *$} & \multirow[t]{2}{*}{$(1 \overline{4} 4)[81 \overline{1}]$} & 9.74 & 45 & 0 & \\
\hline & & 99.74 & 90 & 45 & \\
\hline$A$ & $(914)[111 \overline{5}]$ & 45 & 35.26 & 0 & \\
\hline$\overline{\mathrm{A}}$ & $(\overline{1} \overline{11} 5)[\overline{9} \overline{1} \overline{4}]$ & 225 & 35.26 & 45 & \\
\hline B & $(15411)[726 \overline{19}]$ & 45 & 54.74 & 45 & \\
\hline$\overline{\mathrm{B}}$ & $(\overline{7} \overline{26} 19)[\overline{15} \overline{4} \overline{11}]$ & 105 & 54.74 & 45 & \\
\hline $\mathrm{C}$ & $\{334\}\langle 22 \overline{3}\rangle$ & 135 & 45 & 0 & \\
\hline
\end{tabular}


Table 4. Summary of the different significant curve points of AA6082 of Figure 11 (DSC curves).

\begin{tabular}{ccc}
\hline Event & kind of reaction & Type of precipitates \\
\hline $\mathbf{1}$ & exothermic & GP zones formation \\
$\mathbf{1}^{\prime}$ & endothermic & GP zones dissolution \\
$\mathbf{2}$ & exothermic & $\beta^{\prime \prime}$ formation \\
$\mathbf{2}^{\prime}$ & endothermic & $\beta^{\prime \prime}$ dissolution \\
$\mathbf{3}$ & exothermic & $\dot{\beta}^{\prime}$ formation \\
$\mathbf{3}^{\prime}$ & endothermic & $\beta^{\prime}$ dissolution \\
$\mathbf{4}$ & exothermic & $\beta$ formation \\
$\mathbf{4}^{\prime}$ & endothermic & $\beta$ dissolution \\
& & \\
\hline
\end{tabular}

Table 5. Values of boundary energy $\left(E_{b}\right)$ and dislocations energy $\left(E_{d}\right)$.

\begin{tabular}{cccccc}
\hline ECAP passes & $\mathbf{d}_{022^{\circ}}(\boldsymbol{\mu} \mathbf{m})$ & $\bar{\gamma}\left(\mathbf{J} / \mathbf{m}^{2}\right)$ & $\mathbf{E}_{\mathbf{b}}(\mathbf{J} / \mathbf{g})$ & $\boldsymbol{\rho}\left(\mathbf{1 0}^{\mathbf{1 4}}\right) \mathbf{m}^{-2}$ & $\mathbf{E}_{\mathbf{d}}(\mathbf{J} / \mathbf{g})$ \\
\hline 0 & 24.55 & 0.534 & 0.016 & 0.01 & $3.9410^{-4}$ \\
1 & 2.46 & 0.444 & 0.13 & 5.36 & 0.21 \\
2 & 1.26 & 0.488 & 0.28 & 11.67 & 0.46 \\
4 & 0.81 & 0.537 & 0.48 & 8.69 & 0.34 \\
6 & 0.85 & 0.521 & 0.45 & 7.91 & 0.31 \\
8 & 0.65 & 0.553 & 0.62 & 7.01 & 0.27 \\
\hline
\end{tabular}

